\title{
EXPERIENTIAL LEARNING AND CRITICAL REFLECTION AS A TOOL FOR TRANSFER OF BUSINESS KNOWLEDGE: AN EMPIRICAL CASE STUDY OF A START-UP SIMULATION INTERVENTION FOR NASCENT ENTREPRENEURS
}

Ingrid le Roux and Barnard Steyn

Department of Business Management, University of Pretoria

\begin{abstract}
This paper investigates the impact of venture start-up simulation on participants' learning; it is concerned specifically with the relationship between experiential learning theory and critical reflection within venture start-up simulation. This was carried out in empirical investigation of a simulation training game used to train entrepreneurs in a formal setting. The findings show significant improvement in their knowledge of finance, marketing operations and information use. Participants reported increased skills and intended behavioural changes in their own ventures. Finally, there was empirical support for the fact that critical reflection during experiential learning can greatly improve the standard of learning and has an immediate effect on participants' behaviour.
\end{abstract}

JEL J24, M53

\section{1 \\ Introduction}

It is widely accepted that the growth engine for economies worldwide is entrepreneurship. The challenge for governments, universities and schools has been to encourage entrepreneurship among the general population. Over time, there have been many studies on entrepreneurial characteristics: personal characteristics, traits, resource requirements and background. Some entrepreneurs reveal critical elements of success, while others reveal nothing at all. However, it has become apparent that, if entrepreneurship is to flourish, then there has to be education specifically in entrepreneurial development (Broembsen, Wood \& Herrington, 2005: 8).

Past and current research has revealed that simulation can be used successfully to train nascent entrepreneurs. The success of this technique lies in the strength of its training mechanism - experiential learning. It has been shown that entrepreneurs often learn in an experiential manner owing to the nature of their work environments. Furthermore, it has also been acknowledged that experiential learning can be greatly improved by incorporating critical reflection into the experiential learning and simulation environment (Politis, 2005: 399; Cope, 2003: 430; Fripp, 1997: 141; Bourner, 2003: 269; Kolb \& Kolb, 2005: 194; Wolmarans, 2006: 355).

It is important to understand the significance of simulation and its potential for knowledge transfer, because, in South Africa, there are not enough successful growing businesses, and not nearly enough successful entrepreneurs for the sustained economic development needed by the country. Furthermore, there is a very high failure rate among start-up ventures, perhaps as high as $85 \%$. The South African government is in the process of trying to change this alarming situation, but one of the biggest hurdles faced by both the government and the country as a whole is lack of knowledge and experience in the nascent entrepreneurial population (Broembsen et al., 2005: 25).

In view of the significant potential contribution of simulation to knowledge transfer, the questions that have to be asked are, first, 
does knowledge transfer really occur during simulation? And then, what knowledge, if any, is being transferred to participants? Finally, is this the correct knowledge to lead to more start-ups?

This paper explores the answers to these questions by discussing an empirical study conducted during several simulation-training interventions across South Africa. The study makes use of a pre-simulation measurement of the participants' knowledge level, and a post-simulation measurement. Finally, there was a reflected pre-intervention measurement, in which participants were asked to critically consider their knowledge level and content before the simulation, from the perspective of their insights after the intervention.

\section{2}

\section{Experiential learning}

Experiential learning can be defined as: 'a method of learning that involves a variety of a person's mental capabilities...it exists when a learner processes information in an active and immersed environment' (Feinstein, Mann \& Corsun, 2002: 733). Kolb (1984) describes experiential learning as a process which must 'involve [learners] fully, openly, and without bias in new experiences from many perspectives; they must be able to create concepts that integrate their observations into logically sound theories; and they must be able to use these theories to make decisions and solve problems.'

Prominent twentieth century authors like Jung, Dewey, Piaget and others initially conceptualised the theory of experiential learning. However, Kolb (1984) was perhaps the first to synthesise all these different views and ideas into a workable representation of what the brain does when experiential learning occurs. Kolb has developed six preconditions that must be taken into consideration during experiential learning.

- Learning is a process, not a once-off event.

- All learning is merely relearning and alteration of previous 'patterns' that the brain has created through prior experiences.
- Learning requires the resolution of conflicts where differences exist in previously learned patterns.

- Learning is a holistic process within the brain and is not only cognitive or experienced or felt.

- Learning requires synergy between people and the environment in which they find themselves.

- Learning is a process whereby knowledge and experience are created, which the brain can 'reuse' when necessary to solve problems and conflicts similar to those which created the initial learning (Kolb \& Kolb, 2005: 194).

Learning is therefore an ongoing process incorporating many variables that have to be considered.

Research conducted by Zull (2004) supports experiential learning theory by identifying, on the biological level, the physical process carried out by the brain during learning. Increasingly more research is revealing that the brain is 'plastic' in nature, and that learning creates an actual physical change in the brain's structure (Zull, 2004: 68). This suggests some permanency in the formation of the patterns.

Experiential learning theory holds that there are four learning styles, and that people appear to prefer one or more of them. These styles are determined by how people resolve conflict about opposing constructs, namely: concrete experience versus formation of abstract concepts, or testing implications versus observation and reflection. From this process of conflict resolution emerge four learning styles: the accommodator, the diverger, the assimilator and the converger (Boyatzis \& Kolb, 2002: 6).

Experiential learning requires an intact process to occur in the brain for the event to become knowledge/experience. People appear to accomplish this in their own unique manner and style. It is further apparent that, if people learn in a style similar to their own preferred style, then the learning process becomes easier. However, if people learn in a style foreign to them, then the process becomes more difficult. The quality of learning will probably be lower and the content more easily forgotten. Consequently, the style 
that learners prefer should be considered by facilitators during training interventions. Perhaps the power of experiential learning lies simply in the fact that physical experience and direct observation of phenomena result in the practical wisdom created by these experiences. This eventually creates practical knowledge that aids the entrepreneur in future venture creation (Politis, 2005: 401).

\subsection{Critical reflection as part of experiential learning}

For experiential learning to move through the entire process from concrete experience to active experimentation, whether it be from a 'real-world' experience or from a simulation, critical reflection on the event - its implications, alternatives and consequences - enhances learning. The concept of critical reflection is common in higher education. Higher education aims at giving people the skills to scrutinise a phenomenon or event and critically consider all possible outcomes and scenarios, thereby developing the best solution or answer.

Reflection can be defined as learners processing their experiences in such a way that they know what they are doing and, perhaps most importantly, why they are doing it (Boud, 1999: 123). The process of knowing how and why one is doing, or did, something, is critical reflection, as it gives time for the mind to consciously consider events. Critical analysis of one's behaviour, decisions, emotions and thoughts on a subject, whether or not the event resulted in a positive outcome, allows the experience to become 'cemented' into knowledge. Critical reflection helps stimulate the 'plastic' brain into changing its state and it permanently alters the previous pattern for that particular type of problem. In this way, the newly acquired knowledge becomes 'experience'. Should it be necessary, the brain can retrieve and reuse this altered pattern for any similar problems it may encounter in the future (Daudelin \& Hall, 1997: 14).

Critical reflection and thinking aid selfdiscovery and questioning, which allows people to develop a comprehensive view of the problem, event or phenomenon. Critical thought forces people to reconsider their assumptions and beliefs, thereby emancipating themselves from previous possibly limiting perspectives. Assumptions are altered and a new paradigm is created (Kayes, 2002: 138).

Extrapolating the relationship between reflective thought and its influence within experiential learning theory creates a better understanding of how simulations can alter 'ground level' behaviour in people. Furthermore, assessing the relationship can help create a better understanding of how entrepreneurs learn and how interventions can aid entrepreneurs.

Reflective learning during simulation can be a powerful tool for allowing participants to gain a deeper and longer-lasting impression of delivered knowledge. Reflective practice can greatly strengthen methods of knowledge delivery, if employed in a responsible, correct manner. Critical reflection should be considered part of experiential learning, not as a separate action following experiential learning. Good reflective practice should be incorporated into a simulation to create a learning environment in which participants can easily and comfortably move through the entire process of experiential learning. They could then leave the simulation with better tools for problem analysis and solving.

\subsection{Experiential learning within simulation}

Experiential learning occurs within simulation, and reflective practice becomes embedded in the experiential learning process. A simulation is a representation of a real-world system, so a simulation can be considered to be a model. Cooper and Schindler define a model as a representation of a system constructed to study some aspect of that system or the system as a whole (Cooper \& Schindler, 2003: 55).

However, in simulation, the model is constructed, not to study a specific aspect, but rather to enable participants to gain insight into that specific system during participation in the model. Experiential learning, which occurs within simulation, involves education, training and learning, and makes use of all three constructs either simultaneously or individually to achieve the aim of the simulation. 
Experiential learning within simulation is a powerful tool in the management sciences, on account of the difficulty in replicating realworld conditions in a classroom. However, in experiential learning, the facilitator is better able to re-create real-world conditions, rendering the participants' experience more rewarding and more applicable to their work environment. Simulation often allows a student deeper insight into a particular need, and is flexible enough to adapt the simulation to the person's specific needs (Fripp, 1994: 29). There is also strong evidence that simulation enhances understanding of management concepts, and that gaming can help to develop managers who are able to deal with turbulence and ambiguity in the work environment (Wolfe, 1998: 310; Wolfe \& Luethge, 2003: 69). The classic work by Gibb indicates that, if enterprise, which he considers to be entrepreneurial behaviour, can be acquired through experience, it can be enhanced through training and simulation (Gibb, 1993: 19; Wolmarans, 2006: 353).

3

\section{Background to simulation}

\subsection{Training, education and learning}

In the marketplace of education, there are many training methods, including games, role-playing and computer simulations, all falling under the term 'simulation'.

Before discussing simulation and experiential learning, it is important to distinguish between training, education and learning. Generally, training encompasses practical decision-making, communication skills and on-the-job action. Training is concerned with a process, whereas education places emphasis on learning facts and figures. Education thus focuses on the product rather than the process (Feinstein et al., 2002: 739). Feinstein et al. (2002) distinguish between education and training: training is comprised of a finite set of tasks, duties and responsibilities associated with an organisational role. The knowledge of how to be a successful 'role performer' is transferred from the trainer to the trainee. Education is more general, and is not targeted at creating successful role performance. It develops critical thinking skills and the ability to ask questions and find answers. It can further be considered an act or a process whereby knowledge is given to students primarily in lectures based on theory.

While training encompasses the learner's becoming accustomed to and skilled in a certain behaviour or role performance encountered during the training, learning requires a student to gain knowledge, skill and comprehension through execution, which can lead to permanent changes in behaviour, and further the mastery of the skill and knowledge acquired (Pretorius, 2001: 27).

\subsection{Simulation games}

Games of a strategic type are believed to have originated in China circa 3000 BCE. It is thought that they were mainly military in nature, probably a precursor to modern-day chess (Feinstein et al., 2002). Games have changed and advanced dramatically since 3000 BCE and today's simulation games teach/train in numerous ways.

Classic authors like Elgood (1988, in Nieman \& Niemann, 2004) have established certain boundaries within which a game should fall if it is to be considered a game. First, it must have a sufficiently clear framework to ensure that the game is the same exercise whenever it is used. Secondly, it must take place within time frames and different stages, while participants should influence the game's progression. Thirdly, before the commencement of the game, some criterion must be identified by which to judge or measure performance. Lastly, there must exist, for the purpose of its operation, a certain amount of documentation, computation, administrative/ behaviour skill and physical material (Nieman \& Niemann, 2004: 3).

The paper has already established that simulation involves experiential learning, which encompasses education, training, and learning. How simulation games transfer knowledge to participants will now be explored further.

\subsection{How simulation games teach}

Venture start-up courses often use lecturing, case studies and practical sessions, while 
simulations use hands-on activities and a prescribed setting with rules, and aim to give participants a better understanding of what creates success in complex business situations (Fripp, 1994: 29).

Knowledge transfer occurring during a simulation is strongly linked to learning from mistakes, by 'making' a mistake, probably unsuspectingly. Feedback plays an important role in this process, as it highlights participants' errors and, most importantly, shows why they made the mistake and its consequent result. Feedback usually occurs after a given time has elapsed (Feinstein et al., 2002: 736). Understanding the reasons for a certain outcome (reflection) helps reinforce the participant's experience and, through either exploration or exploitation, to relate it to the person's career experiences and their translation into entrepreneurial knowledge (Politis, 2005: 402).

A simulation further creates a hypothetical scenario in which the participants are faced with predetermined scenario variables in which they must participate and make decisions. The scenarios are linked to a particular concept that the facilitator wants to impart to the participants. They have to consider all possible variables before them and judge which decision would be best to solve the problem presented by the scenario. The act of choosing forces participants to analyse, evaluate, synthesise and possibly create novel solutions (Pretorius, 2001: 106). They have to reflect on the potential effects of decisions, thereby enhancing the scope of their learning from such experiences.

During simulations, participants learn under pressure about 'how' to do things, and discover personally 'what with'. The learning environment is therefore typically founded on learning by doing (Gibb, 1993: 19). Furthermore, the essence of enterprise should be brought into the learning environment with a project management task structure, to facilitate learning under conditions of uncertainty (Gibb, 1993: 21). The emphasis is therefore on the fact that the more realistic the learning environment, the more probable it is that learning will have the desired effect.

A simulation game naturally implies competition between participants/teams, with each round of the game resulting in winners and losers. According to Elgood (1988, in Nieman \& Niemann, 2004)), a game also refers to an activity that is repeated and bounded by rules, and in which participants learn skills and abilities that will be relevant each time the game is played, so that they can improve within the game's context (Nieman \& Niemann, 2004: 2).

According to Feinstein et al. (2002), cognitive research is starting to reveal the early benefits of simulation. Researchers are beginning to understand why and how the brain stores, retrieves and uses information and knowledge. The classic author Hyman (1978) stated that simulation is an effective method of learning for participants, because: 'People learn to act by acting; they learn to live by living; they learn to do by doing' (Feinstein et al., 2002: 740). Hyman also pointed out that the human mind learns through stories. Stories are taken in, stored and retrieved, and perhaps even 'told'. He further believes that people use the learned stories to develop a script (pattern) on which to act in specific situations. A simulation could possibly give a participant a different script on which to base his/her actions in a given situation (Feinstein et al., 2002: 740).

Whatever the form of simulation, it does several things simultaneously. It combines the best of experiential approaches with more traditional learning methods, for, while simulation can enhance, it cannot replace traditional learning methods (Pretorius, 2001: 116). Simulation provides heightened levels of motivation, teamwork, a risk-free environment, variety, fast reliable feedback, preparation for real-world experiences and the ability to examine one's own performance (Feinstein $e t$ al., 2002: 740; Nieman \& Niemann, 2004: Fripp, 1997: 138).

However, simulation has its drawbacks. The type of subject matter it uses is limited, and simulating the learning of facts is difficult. A knowledgeable facilitator is crucial to success and simulation is a weak tool when used as a 'stand-alone' training mechanism. The most prominent disadvantages of simulation are simply its inability to take into consideration all the potential scenarios, environmental conditions and combinations that actually 
exist in the real world, and the fact that experiential learning and critical reflection cannot successfully occur without a skilled and experienced facilitator involved in the entire simulation process (Pretorius, 2001: 114).

\subsection{Facilitator's role}

The facilitator's role in simulation games is very important for the potential success of the simulation and the desired knowledge transfer. Classic authors like Gibb (1993) give considerable attention to the issue. Gibb (1993) believes that the facilitator's role is that of a guiding partner in the process, and must focus on recognising different ways in which people learn, understand the learning process and facilitate it. The facilitator should move away from the traditional teaching methods, while moving towards a learning process that is not tightly controlled or processed. The emphasis should be on the delivery of knowledge and the examination of understanding. 'In certain respects, the tutor is more important if learning is to be assured' (Gibb, 1993: 22).

According to Elgood (1988, in Nieman \&Niemann, 2004: 4) the role of facilitator should be:

- to understand and prepare for the game

- to explain to participants what is happening

- to decide on the number of teams and their composition

- to explain the objectives of the game

- to teach within the game situation

- to do a review (feedback/reflection) session.

DeFranco and Reich (1994, in Feinstein et al. (2002)), state: 'The tactics of delivery and style and goal orientated activities form the basis of the teacher's success in being able to interest students in the topic, then guide them through meaningful exercises that lead to a competent grasp of the subject matter.' Further simulation then allows the students to practise their new skills.

According to Pretorius, Nieman \& Van Vuuren (2005), the role of the facilitator is highly influential on the potential success of a simulation game. The facilitator must follow the participants' progress throughout the entire process, seeking opportunities to explain theory and clarifying theoretical concepts and principles. Simulation games, as mentioned above under the disadvantages of simulation, cannot be used as a stand-alone tool for training. The simulation game is merely a tool to be used in conjunction with other learning methods (Pretorius, 2001: 121).

\section{4 \\ Case study - Successoneur ${ }^{\mathrm{TM}}$ Business Decision Simulator (SBDS)}

SBDS is a basic business start-up simulation board game that forces constant decisionmaking. The board game resembles a monopoly board, in that participants can move their game pieces around the 'growth lane' of the board, as well as through a 'trade lane', using a throw of the dice to determine how far each piece may move at a time.

The aim of the game is to start a business or businesses, and trade to generate profit. The player with the premier balance sheet (measured by net asset value and return on investment) at the end of the game is the winner.

At the start of the game, each player receives limited resources of cash, credit (a home loan), a pension, and randomly-dealt market share cards. Market share cards are colour-coded, each colour relating throughout to the same business. There are three different businesses, each representing different turnover rates and profit margins. Each business started must have a concept (idea/opportunity), facility, equipment, distribution channel and expertise. Each card represents one element of what is necessary in the real world to be able to start a business, so that all five are necessary to be able to start trading in the game.

During the start-up phase, and once players have started trading, the game simulates real-world business situations, such as strikes, liquidity issues or competitors, by introducing several different contingencies into the game. These are: growth and trade opportunity cards, variable cost cards 
and contingency cards. Each card requires players to act (make a decision one way or the other) in a certain manner, such as 'do maintenance' or 'pay interest' or 'business for sale'. This allows for the players' past actions to be brought to fruition or forces them to make certain decisions that will affect them in the future. Game/business strategy becomes important, as the players with the most market share would naturally be in a better position than players with less market share. Thus gaining and protecting market share for the specific business type in which the player is trading becomes a highly strategic issue.

The simulation continues over several days, where over time all strategic issues are brought to the fore. When a strategic or other issue occurs during the simulation, play is halted and a short interactive lecture is given on the theory supporting the strategic issue that has just occurred. Once feedback on an issue and reflection have been completed, the game playing resumes until another important issue occurs. Thus, through a form of trial and error, the participants are given a hands-on experience supported by theory, which should allow for a much greater learning experience than a standard lecture or stand-alone simulation might have provided. The interactive sessions and immediate opportunities for reflection lead to opportunities for altering chosen strategies after reflecting on the new information given by facilitators.

As the game progresses, more complex issues are introduced, such as secret strategies, bank interventions, calling for liquidity checks, new opportunities, joint ventures and partnership opportunities. Finally, there is a debriefing on all the issues that have arisen, which forms a crucial part of the training and simulation game. The debriefing is dependent largely on questions seeking a reflective response. Study material containing theory supports the participants in the form of 'take-home learning'.

\subsection{The basic knowledge that Successoneur $^{\mathrm{TM}}$ aims to transfer}

The simulation game aims to make participants aware of certain basic but important theoretical aspects, such as:

- basic requirements for any venture start-up
- the start-up and management processes

- the importance of market share

- strategy and its role in a venture

- growth issues (financial, structural and strategic)

- venture development patterns and life cycles

- debt-financing, financing and leverage and their effects on profit statement and balance sheet

- competitors within markets

- income and expenditure patterns

- cash-flow shortages (experienced first hand).

At the start of the day, as well as during the simulation, the participants are given the opportunity of reflecting on what they have learned, and how they can apply it in their own venture situations or apply in their own ventures what others have experienced in theirs. The facilitators regularly stop play to demonstrate specific occurrences of the venture start-up principles. Each time this happens, participants have to reflect on how they would apply these occurrences to their own ventures.

Thus the Successoneur ${ }^{\mathrm{TM}}$ business simulation training game, in conjunction with a facilitator, is designed to transfer venture start-up knowledge and related issues to the participants during the training programme.

5

\section{Research objectives of this study}

This study aimed first to measure empirically whether the business simulation transferred knowledge to participants, and to determine what knowledge was transferred. Secondly it was concerned with exploring the role of critical reflection in experiential learning.

6

\section{Methodology}

\subsection{Research design}

This study was a formal one consisting of both a quantitative part and a qualitative part based 
on open questions to improve understanding of the results obtained. The design was a multiple

$\mathrm{O}$

$\mathrm{X}$

Pre-test

Intervention (Simulation)

Before the simulation intervention, participants were tested on their knowledge level regarding constructs developed beforehand, namely: finance, marketing, operations and information. The simulation was then conducted. After the simulation, which is considered to be the intervention, participants were tested on their knowledge level at that stage. The participants were then asked to reflect on their real knowledge level before the intervention, given their insights gained through the intervention. Thus three measurements were created on which to conduct statistical techniques, namely: pre-test perception (test before the intervention); post-test (test after the simulation intervention); and lastly reflected pre-test (test reflecting on what their real knowledge had been before the intervention).

The research environment in which the study took place was multiple training courses presented across South Africa as part of a programme developed for clients and potential clients (borrowers) of the Industrial Development Corporation.

The time dimension was cross-sectional, as the participants' level of knowledge with regard to certain basic business issues was measured on the first day of each training programme, before commencement of training. It was measured again once the training had been completed. The participants were then asked to reflect on their knowledge level both prior to and after the training. The researcher's control over the variables was limited, as there could be very little control over what participants might perceive to be important for them to 'take away' from the training. The study was therefore an ex post facto design, as control of what knowledge has been transferred is highly contextual. The topical scope of the research was designed for depth rather than breadth. The study attempted to draw inferences about the participants' knowledge levels and their own changes in knowledge. The hypotheses were tested quantitatively. group, pretest-post-test with an added 'reflected' pre-test measurement.
$\mathrm{O}$

Post-test
$\mathrm{O}_{2}$

Reflected Pre-test

\subsection{Data collection and sample population}

Data collection was carried out using two questionnaires consisting of 31 questions, excluding demographic questions. Respondents rated each statement on a four-point scale, 4 being 'strongly agree' and 1 being 'strongly disagree'. The data collected was 'expressed as ratio data'. Nominal data pertaining to demographics was collected: age, education level, current employment position and language were all recorded. Qualitative open-ended questions were also asked to support the quantitative results.

The population was all participants (100 persons) in the interventions offered by a university to the participants on behalf of the Industrial Development Corporation (IDC). Participants included existing loan holders, potential loan applicants and employees of firms using IDC finance.

\subsection{Data analysis}

Recorded data was presented in the form of descriptive statistics, with means and standard deviations and an exploratory factor analysis. Exploratory factor analysis was conducted to verify whether the proposed factors represented distinct constructs and to assess the discriminant and construct validity of the measuring instrument used in this study. Exploratory factor analysis (with BMDP - Direct Oblimin) allows testing of specific propositions about the factor structure for a set of variables. Selection for variable inclusion was based on contribution to the Cronbach alphas and the correlation between items within each factor. After rotation, the factor analysis suggested the existence of four factors. Oblique rotation was done because of the expected high correlations between the factors, seeing that the literature review indicated that a correlation between strategy, finance operations and marketing was to be 
expected. The results of the exploratory factor analysis provided evidence of the discriminant validity of the instrument used to measure the constructs (see also Table 3 ).

Thereafter a correlation analysis was conducted to determine the strength of the correlations, whether such correlations existed. Following this, analysis of variance was carried out to compare construct averages between the interventions.

Several open-ended (qualitative) questions were asked in addition to the quantitative questions. These responses were coded according to frequently occurring answers to each question. Their aim was to find support for the quantitative data and to gain insights into participants' skills, learning and future actions as a result of attending the intervention.

7

Findings

\subsection{Demographics of the respondents}

Key biographic data for the respondent set is shown in Table 1.

\section{Table 1}

Biographic data of the sample

\begin{tabular}{|c|c|c|}
\hline Age in years & Frequency & Percent \\
\hline Under 19 & 4 & $4 \%$ \\
$20-29$ & 24 & $24 \%$ \\
$30-39$ & 29 & $29 \%$ \\
$40-49$ & 25 & $25 \%$ \\
50 and above & 18 & $18 \%$ \\
Total & 100 & $100 \%$ \\
\hline Gender & Frequency & Percent \\
\hline Male & 63 & $63 \%$ \\
Female & 36 & $36 \%$ \\
Total & 100 & $100 \%$ \\
\hline Qualification & Frequency & Percent \\
\hline No Grade 12 & 28 & $28 \%$ \\
Grade 12 & 36 & $36 \%$ \\
Certificate & 32 & $32 \%$ \\
Diploma & 1 & $1 \%$ \\
Degree & 2 & $2 \%$ \\
Total & $99^{*}$ & $99 \%$ \\
\hline Field & Frequency & Percent \\
\hline Total & 41 & $41 \%$ \\
Finance & 3 & $3 \%$ \\
IT & 3 & $3 \%$ \\
Engineering & $760 \%$ & $7 \%$ \\
\hline & & $100 \%$ \\
\hline
\end{tabular}




\begin{tabular}{|c|c|c|}
\hline Language & Frequency & Percent \\
\hline Afrikaans & 23 & $23 \%$ \\
English & 8 & $8 \%$ \\
African Language & 69 & $69 \%$ \\
Total & 100 & $100 \%$ \\
\hline Position & Frequency & Percent \\
\hline Top Management & 46 & $46 \%$ \\
Middle Management & 15 & $15 \%$ \\
Operational management & 26 & $26 \%$ \\
Junior & 13 & $13 \%$ \\
Total & 100 & $100 \%$ \\
\hline
\end{tabular}

* Missing response

Forty-six per cent of the participants in the Successoneur ${ }^{\mathrm{TM}}$ Business Decision Simulation training game designated themselves as being in senior management. However, it should be noted that many of the participants are owners of their ventures and therefore may perceive themselves to be holding a senior position. However, in view of the relatively small size of their ventures, defining their position as 'senior' may be interpreted differently from that of a large business and even that of a small business.

Sixty-nine per cent of the participants spoke an indigenous African language, the second highest frequency being Afrikaans. The percentage rankings provide a generally realistic representation of the true language composition of the South African population.

Sixty-three per cent of the participants were male. It is, however, pleasing to note that the difference between the number of women and men present is perhaps not that great, and shows that more and more women are entering the business arena, which has in the past been a male-dominated field.

It is evident from the frequencies that the majority of participants were over 20 years old. This would seem representative of the entrepreneurial population and their involvement in business in relation to age in South Africa. It is interesting to note that $28 \%$ of the respondents had less than what is considered to be a basic education (lower than grade 12).

\subsection{Factor analysis and correlation matrices}

The exploratory factor analysis (done with the post-test intervention data) revealed four independent constructs, namely: Finance, Marketing, Operations and Information. Table 2 (below) is a summary of the factors and means for the associated variables

Table 2

Summary of factors and their associated variables

\begin{tabular}{|l|c|c|}
\hline \multicolumn{2}{|l|}{ Cronbach Alpha= $\mathbf{0 . 7 9 3}$} \\
\hline \\
\hline Variable & Mean & Std Dev \\
\hline Buying insurance influences the income statement, not the balance sheet. & 2.222 & 0.887 \\
\hline I know the basic elements of financial statements. & 2.434 & 0.882 \\
\hline I understand the effect of negative cash flow. & 2.383 & 0.841 \\
\hline
\end{tabular}




\begin{tabular}{|l|c|c|}
\hline I know what solvency means. & 2.565 & 1.001 \\
\hline I understand why some things cannot be part of the balance sheet. & 2.292 & 0.895 \\
\hline I understand how to leverage assets. & 1.868 & 0.751 \\
\hline
\end{tabular}

\begin{tabular}{|l|c|c|}
\hline Factor 2: Marketing & \multicolumn{2}{l|}{ Cronbach Alpha= $\mathbf{0 . 8 0 2}$} \\
\hline & Mean & Std Dev \\
\hline Variable & 2.464 & 0.812 \\
\hline I understand the role of the customer in positioning a product. & 2.353 & 0.872 \\
\hline I understand the relationship between advertising and positioning. & 2.050 & 0.837 \\
\hline I understand the importance of market share in determining sales revenue. & & \\
\hline
\end{tabular}

\begin{tabular}{|c|c|c|}
\hline Factor 3: Operation & & \\
\hline Variable & Mean & Std Dev \\
\hline I know the basic resources needed before a business can start trading. & 2.555 & 0.906 \\
\hline I know the difference between effectiveness and efficiency. & 2.323 & 0.830 \\
\hline I understand how focus on quality influences eventual success. & 2.535 & 0.812 \\
\hline
\end{tabular}

\begin{tabular}{|c|c|c|}
\hline Factor 4: Information & & \\
\hline Variable & Mean & Std Dev \\
\hline Diversity is more about difference in thinking than difference in culture. & 2.323 & 0.767 \\
\hline I know the importance of sharing information with team members. & 2.808 & 0.816 \\
\hline I understand how to get people to work as a team. & 2.767 & 0.843 \\
\hline I can select the important information within the data overload. & 2.404 & 0.819 \\
\hline
\end{tabular}

Strategy was one of the factors that the questionnaire intended to measure. However, the factor analysis did not confirm its existence because of the low Cronbach alpha obtained, and these variables were omitted from further analysis. Double-loading and no-loading variables were also removed to maximise reliability in measurement.
Correlations were reported at all three intervention levels (see Table 3) to determine whether there were differences after the interventions. It could be expected that interrelatedness would be perceived as higher after the intervention, as this was a specific outcome set to be achieved. While there was correlation within factors (as shown by the Cronbachs), correlations between factors were also high. 
Table 3

Correlation matrixes

Correlation matrix for Pre-intervention measurement

\begin{tabular}{|l|c|c|c|}
\hline Factor & Finances & Marketing & Operations \\
\hline Finances & - & - & - \\
\hline Marketing & 0.456 & 0.442 & - \\
\hline Operations & 0.600 & 0.447 & 0.472 \\
\hline Information & 0.359 & - & - \\
\hline
\end{tabular}

\section{Correlation matrix for Post-intervention measurement}

\begin{tabular}{|l|c|c|c|}
\hline Factor & Finances & Marketing & Operations \\
\hline Finances & - & - & - \\
\hline Marketing & 0.658 & - & - \\
\hline Operations & 0.629 & 0.496 & 0.506 \\
\hline Information & 0.547 & 0.528 & - \\
\hline
\end{tabular}

Correlation matrix for Reflected Pre-intervention measurement

\begin{tabular}{|l|c|c|c|}
\hline Factor & Finances & Marketing & Operations \\
\hline Finances & - & - & - \\
\hline Marketing & 0.638 & - & - \\
\hline Operations & 0.653 & 0.518 & 0.586 \\
\hline Information & 0.521 & 0.564 & - \\
\hline
\end{tabular}

Correlations were found to be high among all factors. This was expected and can be attributed to the fact that the intervention focused on transferring knowledge relating to these factors. Each factor was interwoven within the intervention, as successful start-up requires all the elements to be in balance. Successful marketing requires improved operations and leads to improved financial performance. The factors are all elements of a successful start-up and operation of a venture.

\section{8}

\section{Critical analysis}

Table 4 compares pre-intervention, postintervention and reflected pre-intervention means. 


\section{Table 4}

Summary of mean scores between pre-, post- and reflected pre-evaluations and the corresponding F-values

\begin{tabular}{|c|c|c|c|c|c|}
\hline Factor & & & & F Value & $\operatorname{Pr}>\mathbf{F}$ \\
\hline Finances & Pre & Post & Reflect - Pre & \multicolumn{2}{|c|}{ Significance of difference } \\
\hline & 2.688 & 3.443 & - & 192.12 & $<.0001^{* * *}$ \\
\hline & - & 3.443 & 2.294 & 320.02 & $<.0001^{* * *}$ \\
\hline & 2.688 & - & 2.294 & 44.41 & $<.0001^{* * *}$ \\
\hline \multirow[t]{3}{*}{ Marketing } & 2.866 & 3.586 & - & 108.74 & $<.0001^{* * *}$ \\
\hline & - & 3.586 & 2.289 & 415.48 & $<.0001 * * *$ \\
\hline & 2.866 & - & 2.289 & 64.71 & $<.0001 * * *$ \\
\hline \multirow[t]{3}{*}{ Operations } & 3.035 & 3.598 & - & 96.14 & $<.0001^{* * *}$ \\
\hline & - & 3.598 & 2.471 & 68.89 & $<.0001^{* * *}$ \\
\hline & 3.035 & - & 2.471 & 352.30 & $<.0001^{* * *}$ \\
\hline \multirow[t]{3}{*}{ Information } & 2.995 & 3.466 & - & 114.70 & $<.0001^{* * *}$ \\
\hline & - & 3.466 & 2.575 & 307.02 & $<.0001^{* * *}$ \\
\hline & 2.995 & - & 2.575 & 47.45 & $<.0001 * * *$ \\
\hline
\end{tabular}

Note: ${ }^{* *}$ : Highly statistically significant differences between groups

Comparison of the means and F-values revealed that knowledge transfer for the four factors did occur during the simulation, as post-intervention means were significantly higher than pre- and reflected pre-intervention means.

When post- and reflected pre-test means were compared, significant differences were also evident. This indicates that when participants reflected upon the learning, and what they perceived as new knowledge, some type of deeper understanding did occur.

However, perhaps the most interesting finding comes from the comparison between what participants thought they knew before the simulation (pre-intervention means) and what they realised their knowledge had actually been before the intervention (reflected preintervention mean), both based on what they knew after the simulation. Reflected pre- intervention means were significantly lower than pre-intervention means. This difference may confirm a general self-evaluation bias on the part of participants at the start of the course, which led them to overestimate their own knowledge level. When they reflected on their pre-intervention knowledge, their new insights allowed them to realise this.

\section{9}

\section{Analysis of the qualitative questions (open-ended)}

Three open-ended questions were asked in support of the qualitative results. Each response was considered and coded. Questions tended to create a similar type of response, which were analysed and their frequency recorded. This quantitative data is presented below. 
The differences between total scores (tables 5, 6 and 7) within each table is owing simply to the fact that, when respondents ranked more responses as one (1), it meant the factor was more important, whereas when responses were ranked as five (5), the ranking was less important. Respondents identified between one and five elements.

\section{Table 5}

Responses to the question: 'What in your opinion were the greatest contributions of the course to your skills level? Rate them according to importance.'

\begin{tabular}{|l|c|c|c|c|c|c|c|}
\hline Response categories & $\mathbf{1}^{\text {st }}$ & $\mathbf{2}^{\text {nd }}$ & $\mathbf{3}^{\text {rd }}$ & $\mathbf{4}^{\text {th }}$ & Total & $\begin{array}{c}\text { Cumulative } \\
\%\end{array}$ \\
\hline Management, leadership \& business & & & & & & & \\
principles & 32 & 28 & 9 & 0 & 69 & $39.88 \%$ & $39.88 \%$ \\
Thinking preferences & 26 & 10 & 2 & 0 & 38 & $21.96 \%$ & $61.84 \%$ \\
Strategy use and effects & 11 & 11 & 2 & 0 & 24 & $13.87 \%$ & $75.71 \%$ \\
Financial literacy & 10 & 6 & 6 & 1 & 23 & $13.29 \%$ & $89.00 \%$ \\
Planning, leading, organising and & 8 & 5 & 1 & 0 & 14 & $8.09 \%$ & $97.09 \%$ \\
control specifics & 1 & 2 & 2 & 0 & 5 & $2.89 \%$ & $99.98 \%$ \\
Business plan, steps and elements & 88 & 62 & 22 & 1 & 173 & $99.98 \% *$ & $99.98 \% *$ \\
\hline \multicolumn{1}{|c|}{ Total } & & & & & & & \\
\hline
\end{tabular}

* Due to rounding

When the totals of each category were compiled into a more understandable format, it was revealed that the majority of the participants considered improved understanding of management, leadership and business principles to be the greatest benefit of the intervention. The category for management, leadership and business principles was also ranked as most important in the analysis.

'Management, leadership and business principles' were considered separately from their elements 'planning, leading, organising and control', because these were considered to be the tools for the accomplishment of a given scenario (specifically mentioned), whereas management, leadership and business principles were considered to be the more general theoretical component of knowledge transfer.

'Thinking preferences' incorporated the benefit of improved understanding of one's own and other people's thinking and what participants might do differently after the intervention. These improved skills were related to considering situations and problems and then evaluating them differently on the basis of their new knowledge of different thinking patterns.

'Strategy use and effects' referred to the effect of a specific strategy within the venture, its importance and the application that had been of benefit during the intervention.

'Financial literacy' referred to improved understanding of the income statement, balance sheet, cash-flow statement and general economic model of a venture.

Finally, participants mentioned, as a contributor to their skills, improved understanding of the business plan (the necessary steps taken and elements included in compilation).

Responses to the second open-ended question (see Table 6) revealed seven main categories: management, leadership and business principles; financial literacy; teamwork; business plans, steps and elements; thinking preferences; planning, leading, organising and control; and strategy effect (vision and mission). 


\section{Table 6}

Responses to the question: 'In priority order, give your most important ' learnings' from the intervention.'

\begin{tabular}{|l|r|r|r|r|r|r|r|c|}
\hline Response categories & $\mathbf{1}^{\text {st }}$ & $\mathbf{2}^{\text {nd }}$ & $\mathbf{3}^{\text {rd }}$ & $\mathbf{4}^{\text {th }}$ & $\mathbf{5}^{\text {th }}$ & Total & $\mathbf{\%}$ & $\begin{array}{c}\text { Cumulative } \\
\%\end{array}$ \\
\hline Management, leadership \& business & & & & & & & & \\
principles & 25 & 27 & 11 & 4 & 1 & 68 & $26.35 \%$ & $26.35 \%$ \\
Thinking preferences & 35 & 7 & 10 & 1 & 1 & 54 & $20.93 \%$ & $47.28 \%$ \\
Financial literacy & 8 & 15 & 9 & 6 & 0 & 38 & $14.72 \%$ & $62.00 \%$ \\
Team work aspects & 8 & 18 & 9 & 1 & 0 & 36 & $13.95 \%$ & $75.95 \%$ \\
Strategy, vision and mission effects & 9 & 12 & 12 & 1 & 0 & 34 & $13.17 \%$ & $89.12 \%$ \\
Planning, leading, organising and & 9 & 9 & 4 & 1 & 0 & 23 & $8.91 \%$ & $98.03 \%$ \\
control & 2 & 1 & 2 & 0 & 0 & 5 & $1.93 \%$ & $99.96 \%$ \\
Business plans, steps and elements & 96 & 89 & 57 & 14 & 2 & 258 & $99.96 \% *$ & $99.96 \% *$ \\
\hline \multicolumn{2}{|c|}{ Total } & $96 \%$ & & \\
\hline
\end{tabular}

* Due to rounding

Table 6 revealed a somewhat different perspective on the most important things the participants had learned. Management, leadership and business principles were again the most common response, though not by such a large margin as in Table 6. Thinking preferences were a close second and financial literacy third.

Teamwork aspects included the ways in which participants would manage and communicate with the human element of a venture, and whether their human resources management would change in any way after the intervention. The fact that participants valued this as a key learning but not as a contribution to their skills is something of a conundrum.

For the strategy effect, vision and mission were added, as participants frequently mentioned this as a new insight experienced during the intervention. They said that following the intervention they would apply the principle of developing a vision and mission.

\section{Table 7}

Responses to the question: 'In priority order, what would you do differently as a result of this course?'

\begin{tabular}{|c|c|c|c|c|c|c|c|}
\hline Response categories & $1^{\text {st }}$ & $2^{\text {nd }}$ & $3^{\text {rd }}$ & $4^{\text {th }}$ & Total & $\%$ & $\begin{array}{c}\text { Cumulative } \\
\%\end{array}$ \\
\hline $\begin{array}{l}\text { Apply management, leadership \& } \\
\text { business principles }\end{array}$ & 35 & 16 & 9 & 1 & 61 & $34.58 \%$ & $34.58 \%$ \\
\hline Use thinking preferences & 23 & 10 & 4 & 1 & 38 & $21.71 \%$ & $56.29 \%$ \\
\hline Apply team work aspects & 11 & 13 & 4 & 1 & 29 & $16.57 \%$ & $72.86 \%$ \\
\hline Use strategy elements & 3 & 12 & 7 & 0 & 22 & $12.57 \%$ & $85.43 \%$ \\
\hline Apply financial insights & 7 & 8 & 3 & 1 & 19 & $10.85 \%$ & $96.28 \%$ \\
\hline Business plans, steps and elements & 5 & 1 & 0 & 0 & 6 & $3.42 \%$ & $99.7 \%$ \\
\hline Total & 84 & 60 & 27 & 4 & 175 & $99.7 \% *$ & $99.7 \% *$ \\
\hline
\end{tabular}

*Due to rounding 
Table 7 revealed some interesting results. The majority of the participants would approach management and leadership differently, and would apply learned business principles after the simulation. Secondly, participants revealed that they would apply the 'thinking preferences' principles more often, and use teamwork to improve the results of their existing ventures.

General aspects reported by participants included issues like enjoyment of the course: 'I learned so much without even knowing that I learned' or 'for my venture I am going to change this and that', and more. The learning impact of reflection after the intervention appeared to contribute strongly to their future planned actions. Ultimately, changing behaviour is the crux of learning.

Tables 5, 6 and 7 display some interesting trends when the results are compared, namely:

- Many more responses were received for learning (258) than for skills (173) and actions (175), suggesting that the things learned outranked the skills acquired. That is to be expected after a four-day intervention.

- Teamwork aspects were reported for learning and actions but not for skills, suggesting that respondents did not acquire the latter during the intervention. However, they had become aware of the importance of teamwork, which was seen as important enough to warrant action.

- Management, leadership and business principles ranked first for skills, learning and actions, confirming that the principal theories are essential in any training.

\section{0}

\section{Implications}

With statistical evidence that knowledge transfer did occur and supporting evidence that critical reflection and thought about new learned knowledge created deeper understanding, the implications would be that, as an experiential learning tool, simulation can be valuable for entrepreneurial educators who wish to create meaningful interventions with business people/entrepreneurs, nascent or otherwise.
Successful interventions are crucial to economic growth, and business educators should consider replication of this intervention.

Critical reflection appears to create an 'ahha' moment. This enlightening moment could possibly be considered the completion of the experiential learning process, with the final cementing of knowledge and the transformation of learning into experience occurring. The final critical reflection and consideration allows participants to make the knowledge their own by adapting it to one of their own preferred learning styles, thus making recollection easier and longer lasting. It can further be said that critical reflection and the process of personalising the newly acquired knowledge forces the plastic brain to alter its state and change previously learned patterns.

The open-ended questions revealed that numerous different knowledge elements had been transferred to the participants. However, knowledge relating to issues of 'management, leadership and business principles' was the most frequently cited. This finding supports what is generally known about the poor state of management and leadership acumen in South Africa. Business educators should take cognisance of the alternative learning methods to improve small venture start-ups.

The qualitative data was intended to supplement the quantitative data, and support the hypothesis that knowledge transfer did occur. However, it has been noted that the type of knowledge transferred to participants was highly contextual and personal. Generally, the knowledge 'need' is filled, and what knowledge the participants require and communicate to the facilitator is most commonly transferred to participants during the simulation (Le Roux, Pretorius \& Steyn, 2006: 19). Business educators should therefore realise that the individual requirements of participants vary significantly. Educators should consider stratifying education programmes, in order to group participants with similar needs meaningfully.

Simulation, experiential learning and critical reflection within experiential learning create in combination a formidable training and teaching tool. It is thought that this combination and integration of different theories and 
different schools of thought create a shift in training and teaching methods that do or do not use simulation, Further, this theoretical amalgamation can be applied to entrepreneurial training, which eventually helps students develop the knowledge and experience integral to business creation. Such businesses would be sustained in long-term growth existence.

\section{1}

\section{Limitations}

Limitations of the study are mainly owing to the fact that the study examines 'soft issues' in experiential learning and therefore certain inferences had to be made. Thus the broad changes in knowledge levels have been recorded only in a 'reflected' manner rather than to their actual extent. Furthermore, it is impossible to determine to what extent the facilitators rather than the simulation game itself were responsible for the knowledge transfer.

A second limitation is that the questionnaire made use of both perceptual and factual questions. The combination was chosen by the researchers to prevent the participants taking fright at what looked like an examination-type questionnaire. The perceptual results should therefore be interpreted with caution. The fact that participants had time to reflect, however, limited this problem to some extent.

Finally, the role and effect of the training facilitators, their knowledge and experience, may have significantly altered the outcome of such an intervention. The intervention used in this study involved two highly qualified facilitators, each with personal start-up experience, who could pay attention to individual questions and the participants' personal situations. There is thus the possibility that different facilitators might influence the outcome of the findings. Moreover, simulation games cannot be used as a stand-alone tool for training, being merely a tool to be used in conjunction with other learning methods (Pretorius, 2001: 121).

A possible final limitation was self-evaluation bias, although the study design, to a great extent, was meant to counter this.

\section{2}

\section{Acknowledgements}

Acknowledgment is due to the IDC, specifically Mr Eric Langalakhe Mahamba Sithole (Head of the IDC Learning and Development External Department), for his foresight in instigating this course. The identification of funding to effect the course allowed access for many previously disadvantaged participants. Initial reports on results appear to have significantly influenced economic activity.

\section{References}

1 BOUD, D. (1999) "Avoiding the traps: Seeking good practice in the use of self assessment and reflection in professional courses", Social Work Education, 18(2): 121-132.

2 BOURNER, T. (2003) "Assessing reflective learning, education and training", 45(5): 267-272.

3 BOYATZIS, R.E. \& KOLB, D.A. (2002) "Learning styles and adaptive flexibility: Testing experiential learning theory", Management Learning, 33(1): 5-33.

4 BROEMBSEN, M.V.; WOOD, E. \& HERRINGTON, M. (2005) "Global entrepreneurship monitor" South African report.

5 COOPER, D.R. \& SCHINDLER, P.S. (2003) Business Research Methods ( $8^{\text {th }}$ ed.) McGraw Hill: Boston.

6 COPE, J. (2003) "Entrepreneurial learning and critical reflection: Discontinuous events as triggers for 'higher-level' learning", Management Learning, 34(4): 429-450.

7 DAUDELIN, M.W. \& HALL, D.T. (1997) "Using reflection to leverage learning, training and development", December 13-14.

8 FEINSTEIN, A.H.; MANN, S. \& CORSUN, D.L. (2002) "Charting the experiential territory: Clarifying definitions and uses of computer simulation, games and role play", Journal of Management Development, 21(10): 732.

9 FRIPP, J. (1994) "Why use business simulations?", Executive Development, 7(1): 29-32.

10 FRIPP, J. (1997) "A future for business simulations?", Journal of European Industrial Training, 21(4): 138-142.

11 GIBB, A.A. (1993) "The enterprise culture and education: understanding enterprise education and its links with small business, entrepreneurship and wider educational goals", International Small Business Journal, 11(3): 11-34. 
12 KAYES, D.C. (2002) "Experiential learning and its critics: Preserving the role of experience in management learning and education", Academy of Management Learning Education, 1(2): 137-149.

13 KOLB, D.A. (1976) "Management and the learning process", California Management Review, XVIII(3): 21-31.

14 KOLB, D.A. (1984) Experiential Learning: Experience as the Source of Learning Development. Prentice Hall: New Jersey.

15 KOLB, A.Y. \& KOLB, D.A. (2005) "Learning styles and learning spaces: Enhancing experiential learning in higher education", Academy of Management Learning \& Education, 4(2): 193-212.

16 LE ROUX, I.; PRETORIUS, M. \& STEYN, B. (2006) "Transferring entrepreneurial skills: An empirical study of simulation", paper presented at the SAIMS conference, Stellenbosch, Cape Town, September.

17 NIEMAN, G. (2003) "Financing an entrepreneurial venture", in Nieman, G., Hough, J. \& Nieuwenhuizen, C. (eds.) Entrepreneurship: A South African Perspective. Pretoria: Van Schaik.

18 NIEMAN, G. \& NIEMANN, W. (2004) "The use of a computerized simulation game in teaching logistics in South Africa: An exploratory study", paper presented at the $9^{\text {th }}$ ELA-Lognet workshop on New Technology for Logistics Education, Magdeburg, Germany, October.
19 POLITIS, D. (2005) "The process of entrepreneurial learning: a conceptual framework", Entrepreneurship Theory and Practice, July: 399-424.

20 PRETORIUS, M. (2001) "A training model to enhance micro and small business in South Africa", Tswane University of Technology (Pretoria Technikon): Department of Business Management, Pretoria Technikon: Pretoria.

21 PRETORIUS, M.; NIEMAN, G.H. \& VAN VUUREN, J.J. (2005) "Critical evaluation of two models for entrepreneurship education: An improved model through integration", International Journal of Education Management, 19(5): $413-427$.

22 WOLFE, J. (1998) "New developments in the use of simulations and games for learning", Journal of Workplace Learning, 10(6/7): 310-313.

23 WOLFE, J. \& LUETHGE, D.J. (2003) “The impact of involvement on performance in business simulations: An examination of Goosen's 'Know Little' decision-making thesis", Journal of Education for Business, 79(2): 69.

24 WOLMARANS, H.P. (2006) "Business simulations in financial management courses: Implications for higher education", South African Journal of Higher Education, 20(2): 352-366.

25 ZULL, J.E. (2004) "The art of changing the brain”, Educational Leadership, September. 